\title{
Practical thermophotovoltaic generators
}

\author{
(C) B. Bitnar $\llbracket$, W. Durisch, G. Palfinger, F. von Roth, U. Vogt* , A. Brönstrup* , D. Seiler ${ }^{\dagger}$ \\ Paul Scherrer Institut, \\ $\mathrm{CH}-5232$ Villigen PSI, Switzerland \\ * EMPA, CH-8600 Dübendorf, Switzerland \\ $\dagger$ NTB Interstate University for Applied Sciences of Technology, \\ $\mathrm{CH}-9471$ Buchs, Switzerland
}

(Получена 9 февраля 2004 г. Принята к печати 11 февраля 2004 г.)

For use in gas fired thermophotovoltaic systems, a selective emitter made from $\mathrm{Yb}_{2} \mathrm{O}_{3}$ foam ceramic has been developed. This foam ceramic is mechanically stable and FTIR spectroscopy showed that $10 \%$ of the radiation power emitted by the foam can be converted by $\mathrm{Si}$ photocells. The thermal and thermal-shock stability of $\mathrm{Yb}_{2} \mathrm{O}_{3}$ foam ceramic was analysed. The foam passed 200 heating/cooling cycles without major damage. Tubes were manufactured from this material and tested in a thermophotovoltaic demonstration system. An electrical power of $86 \mathrm{~W}$ was achieved at a thermal power of $16 \mathrm{~kW}$. Using a simulation model, a potential efficiency of a thermophotovoltaic system based on our technology applied for the conversion of concentrated solar radiation was estimated.

\section{Introduction}

In thermophotovoltaics thermal energy is used to heat a radiation emitter, which on his part illuminates photocells that convert the radiation into electricity. In this publication two heat sources will be considered: a combustion flame and concentrated solar radiation.

In case of a combustion flame, thermophotovoltaics is a technology of co-generation of heat and electricity without the need of any moving parts. The system efficiency $\eta_{\text {sys }}$, which is defined as electrical power divided by thermal input power, is relatively small: until now, the highest experimentally achieved system efficiency is about 5\% [1].

In case of solar thermophotovoltaics, the possible match between emission spectrum of the radiator and band gap of the photocell material is the advantage compared to direct solar irradiation to the photocell. If a photocell is illuminated by selective radiation with a narrow emission band closely above the band gap of its material, losses due to thermalisation or sub-bandgap transmission are avoided. The efficiecy of a solar cell can strongly be increased compared to direct solar irradiation. Therefore, solar thermophotovoltaics possibly is a way to beat the efficiency limit of existing solar cell technology.

\section{Foam ceramic emitters}

A novel selective emitter to be used in thermophotovoltaic (TPV) systems has been developed. The following requirements to the TPV emitter were defined:

- The selective emission spectrum should be matched to the band gap of $\mathrm{Si}$.

- The structure should be porous, so that the combustion gas can flow through and that combustion can take place in the emitter structure.

- The emitter must be mechanically stable.

\footnotetext{
I E-mail: bernd.bitnar@psi.ch
}

- The emitter must be thermally stable up to operating temperatures of $1800 \mathrm{~K}$.

- The thermal-shock resistance must be high, because the material must withstand numerous heating/cooling cycles without any damage.

A selective emissivity, which is well matched to the band gap of $\mathrm{Si}$, can be achieved by using $\mathrm{Yb}_{2} \mathrm{O}_{3}$ as the emitter material. $\mathrm{Yb}_{2} \mathrm{O}_{3}$ mantle emitters have been investigated for applications in TPV systems in the past $[2,3]$. High TPV system efficiencies could be achieved with mantle emitters, however they suffered from a very poor mechanical stability. The thermal-shock resistivity of $\mathrm{Yb}_{2} \mathrm{O}_{3}$ mantles was sufficient for laboratory TPV systems.

A solution that avoids these drawbacks and fulfils all of the requirements listed above is a $\mathrm{Yb}_{2} \mathrm{O}_{3}$ coated foam ceramic emitter.

Foam ceramics were produced for this work using the polymer-sponge method [4]:

- A polymer sponge with the desired shape and pore size is first fabricated. Sponges in the shape of tubes were used for the current work.

- The sponge is infiltrated with a water-based ceramic slurry. In order to remove excess slurry and avoid pores filled with slurry, the sponge is subsequently passed through a mangle.

- The sponge is then carefully dried, resulting in socalled „green ceramic“. Several samples of such green ceramic foams and emitter tubes are shown in Fig. 1.

- In a subsequent sintering step at temperatures in excess of $1000^{\circ} \mathrm{C}$, the polymer sponge vaporises and the ceramic densifies.

In order to measure the radiation spectrum of these emitter structures, foam ceramic tubes with a diameter of $40 \mathrm{~mm}$ and a wall thickness of $10 \mathrm{~mm}$ were fabricated that could be heated with a $2 \mathrm{~kW}$ butane burner. The emitted radiation was coupled into a Bruker 113 FTIR spectrometer $[3,4]$. Fig. 2 shows the emission spectrum of the $\mathrm{Yb}_{2} \mathrm{O}_{3}$ foam ceramic in comparison to the spectrum of a 


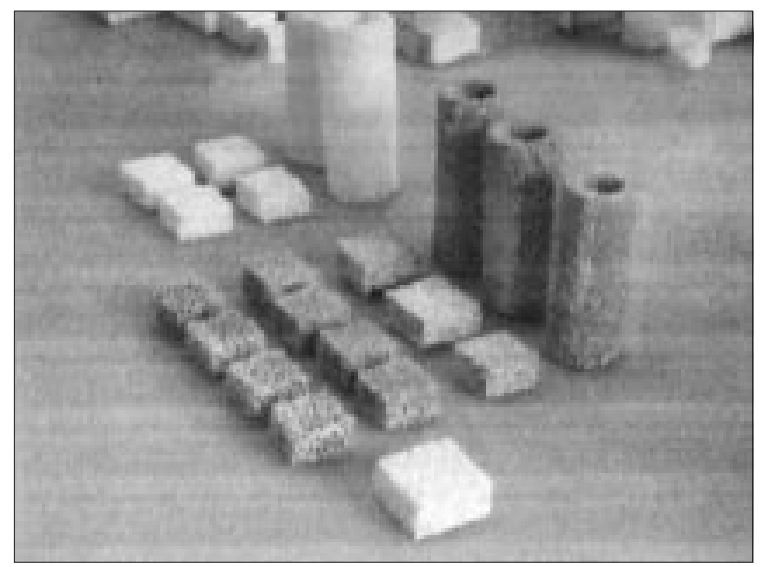

Figure 1. Examples of foam ceramics and foam ceramic emitter tubes. The grey samples are green bodies after infiltration and drying. After sintering the ceramic appears white.

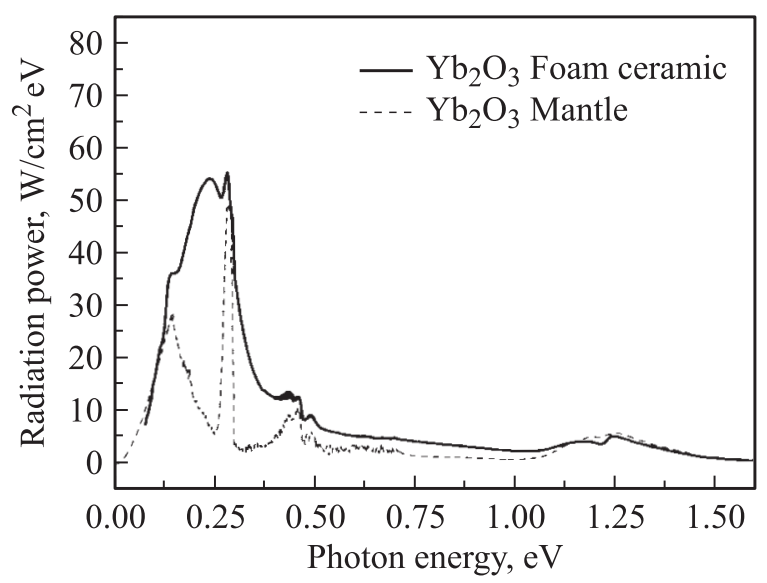

Figure 2. Radiation spectra of a $\mathrm{Yb}_{2} \mathrm{O}_{3}$ foam ceramic and a $\mathrm{Yb}_{2} \mathrm{O}_{3}$ mantle emitter. Both emitters were heated by a $2 \mathrm{~kW}$ butane burner. The temperature of the mantle emitter was $1735 \mathrm{~K}$.

$\mathrm{Yb}_{2} \mathrm{O}_{3}$ mantle [3]. Both spectra show the selective emission peak at a photon energy of $1.25 \mathrm{eV}$, which can be converted by $\mathrm{Si}$ photocells. While the height of this maximum is comparable for the two spectra, the foam ceramic emitter shows a significantly stronger emission at photon energies below $0.5 \mathrm{eV}$. The selectivity, which is defined as radiation power at photon energies larger than the $\mathrm{Si}$ band gap divided by the total emitted radiation power, is consequently only $10 \%$ for the foam ceramic, compared to $20 \%$ for the mantle.

The foam ceramic emitters are mechanically stable. They can easily be handled for mounting in a gas burner, so that they seem to be suitable for an application in TPV systems.

The emitter tubes were heated up to temperatures of $1750 \mathrm{~K}$ with gas burners to study the thermal stability of the stuctures. No thermal instabilites were observed. The surfaces of a surrounding quartz tube and a gold reflector placed above the heated emitter remained clean, indicating that no material evaporated from the samples.
A timer controlled butane burner was built, with which the termal-shock stability of the foam ceramics was studied. This device permitted the automatically operation of the emitters during many heating/cooling cycles. With this method a thermal-shock stability of the foam ceramics over at least 200 cycles has been demonstrated.

\section{TPV prototype system}

The $\mathrm{Yb}_{2} \mathrm{O}_{3}$ foam ceramic emitter was tested in a TPV prototype system [5], which is shown in Fig. 3. In this system the emitter is heated by a $10-20 \mathrm{~kW}$ methane burner. Monocrystalline Si solar cells from RWE Solar (Germany) were glued onto water cooled heatsinks and the frontside was laminated with a special EVA foil. A quartz tube is placed between emitter and photocells to protect the cell surface from contact with the hot combustion gas. The lower end of the cylindrical TPV system is optically closed with a gold reflector. Fig. 3 shows the foam ceramic emitter built into the TPV system.

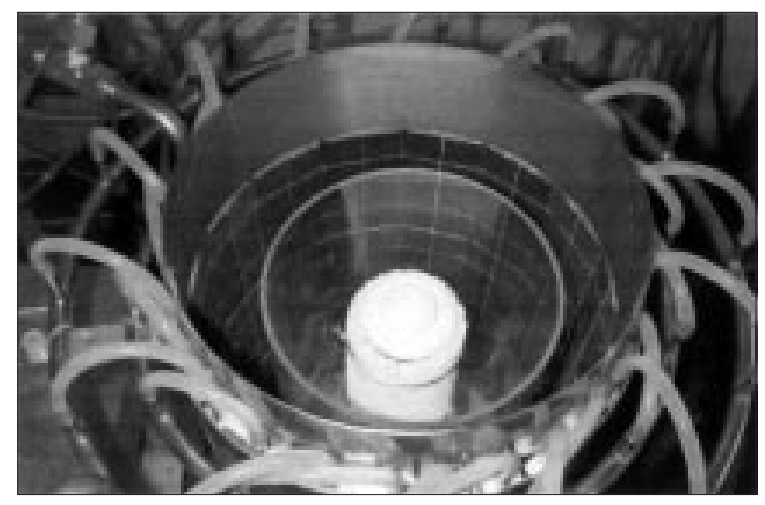

Figure 3. TPV prototype system: In the centre the foam ceramic emitter tube is visible. A quartz tube is placed between emitter and $\mathrm{Si}$ photocells.

Table 1 gives the experimental results achieved with this TPV system. The electrical power $P_{e l}$ and the system efficiency $\eta_{\text {sys }}$ are given for several values of thermal power $P_{t h}$ and air number $\lambda$. The air number gives the amount of combustion air divided by the amount of air for stochiometric combustion. Our experiments demonstrate the feasibility of the novel $\mathrm{Yb}_{2} \mathrm{O}_{3}$ foam ceramic emitter. In earlier experiments by using $\mathrm{Yb}_{2} \mathrm{O}_{3}$ mantle emitters instead of the foam ceramics, a significantly higher electrical power

Table 1. Electrical power $P_{e l}$ and system efficiency $\eta_{\text {sys }}$ achieved with a TPV prototype system with foam ceramic emitter as a function of the thermal power $P_{t h}$ and the air number $\lambda$

\begin{tabular}{c|c|c|c}
\hline$P_{t h}, \mathrm{~kW}$ & $\lambda$ & $P_{e l}, \mathrm{~W}$ & $\eta_{\mathrm{sys}}, \%$ \\
\hline 12 & 1.03 & 60 & 0.50 \\
12 & 1.12 & 54 & 0.49 \\
16 & 1.02 & 86 & 0.54
\end{tabular}




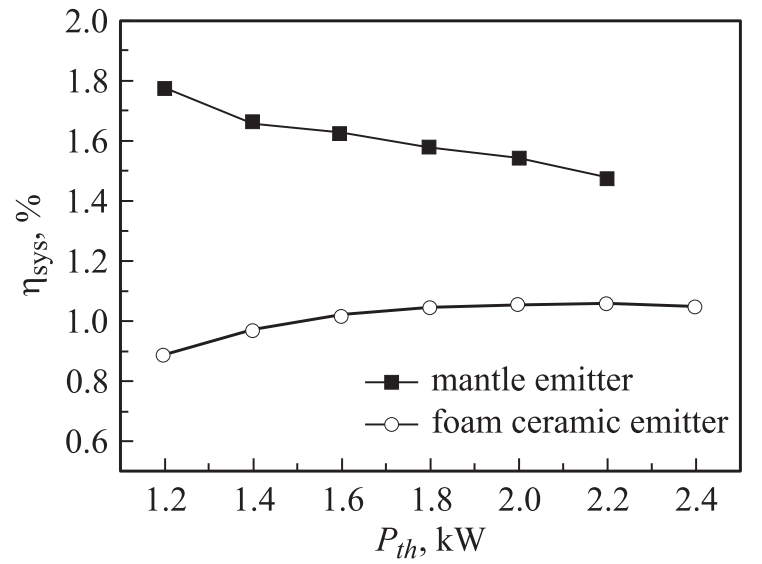

Figure 4. Experimental results achieved with a small TPV prototype system. The system efficiency $\eta_{\text {sys }}$ is given as a function of the thermal power $P_{t h}$ for experiments using an $\mathrm{Yb}_{2} \mathrm{O}_{3}$ mantle emitter (squares) and an $\mathrm{Yb}_{2} \mathrm{O}_{3}$ foam ceramic emitter (open circles).

was achieved [5]. In future, we hope to enhance the selectivity of the foam ceramic emitters by improving the fabrication process.

An increased system efficiency with the existing $\mathrm{Yb}_{2} \mathrm{O}_{3}$ foam ceramic emitter was achived with a small TPV system by the following optimisations:

- Special TPV optimised Si photocells were manufactured, which have a highly reflective rearside $\mathrm{Al}$ mirror and a non-textured frontside to reflect sub-bandgap radiation, for which the cell is transparent, directly back to the emitter. This back-reflected radiation is used for an additional heating of the emitter resulting in a higher emitter temperature for a given thermal power of the burner.

- The $\mathrm{ZnS} / \mathrm{MgF}_{2}$ antireflection coating was optimised for a low reflectivity for the $\mathrm{Yb}_{2} \mathrm{O}_{3}$ emission spectrum.

- The photocell has a low resistant front metallization to reduce the series resistance loss at an illumination level of 5-10 times the sun irradiation, which occurs in our TPV system.

- The cylindrical photocell generator is mostly optically closed by three gold reflectors, leaving only a slit for the escape of the exhaust gas.

A methane burner with a thermal power of $1.2-2.4 \mathrm{~kW}$ was used as a heat source for the emitter. Fig. 4 gives the system efficiency that was achieved with the small TPV system as a function of the thermal power. The experiments with a foam ceramic emitter resulted in a system efficiency of more than $1.0 \%$ between 1.6 and $2.4 \mathrm{~kW}$. This is twice the efficiency achieved by the larger prototype system. With a mantle emitter, up to $1.8 \%$ system efficiency could be obtained.

We plan to build a larger prototype with a similar design allowing a significantly higher system efficiency as the existing demonstration system.

\section{Simulation of solar powered TPV system}

TPV was suggested to be applied in solar concentrator systems to exceed the efficiency limit of one-sun single junction solar cells [7]. In the following, it is estimated, which efficiency is expected by the above described TPV system, if the emitter is heated by concentrated sunlight. For this estimate a simulation model representing the small TPV system was used, which was described in detail elsewhere [2]. The model calculates the electrical power of a TPV system using the geometry, the optical transmittance and reflectance of the inner system surfaces and the spectral efficiency of the photocells. The total radiation power of the emitter $P_{\mathrm{em}}$ is obtained from a combustion model in case of a fuel fired system [2]. For a solar heated TPV system $P_{\mathrm{em}}$ is calculated from:

$$
P_{\mathrm{em}}=P_{\mathrm{sun}} \cdot c \cdot A_{\mathrm{foc}} \cdot\left(1-R_{\mathrm{em}}\right)
$$

with the direct solar irradiation power $P_{\text {sun }}$, the concentration factor $c$, the area of the focused sunlight on the emitter surface $A_{\text {foc }}$ and the reflectivity of the emitter $R_{\mathrm{em}}$.

The model uses the net radiation method [6], which calculates the radiation balance between all surfaces and the total energy balance of the system [2].

A drawing of the simulated solar TPV system is shown in Fig. 5. Through a hole in the top reflector the concentrated sun light is coupled into the system to heat the emitter. The emitter radiation illuminates the cylindrical photocell module built around.

For the discussion of the results, the assumptions of the simulation model have to be considered:

- A uniform temperature over the whole emitter surface was assumed. This assumption seems approximately to be fulfilled, because the brightness of the visible radiation is uniform over the whole gas porous region of the emitter in gas fired TPV experiments.

- The spacing between the single photocells was taken into account by using a view factor, with average values of the photocell efficiency and of the front surface reflectivity were calculated. In the experimental system slits occur between the cells, which were not considered exactly by this simplification.

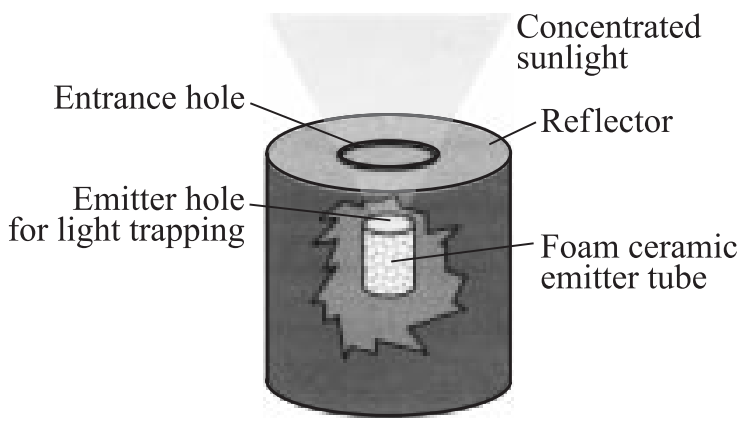

Figure 5. Draft of a cylindrical solar TPV system. 
Table 2. Simulation result of a solar heated TPV system. PSI-TPV is an existing TPV optimised $\mathrm{Si}$ photocell with rear surface reflector, $c$ means the concentration factor of the sun radiation and $T_{\mathrm{em}}$ the resulting emitter temperature

\begin{tabular}{c|c|c|c|c|c}
\hline Photocell & Filter & $c$ & $T_{\mathrm{em}}, \mathrm{K}$ & $P_{e l}, \mathrm{~W}$ & $\eta_{\mathrm{sys}}, \%$ \\
\hline$P S I-T P V$ & Quartz & 1000 & 1750 & 17 & 4.0 \\
$P S I-T P V$ & Quartz & 1000 & 1850 & 25 & 5.9 \\
no FC absorption & & & & & \\
PSI-TPV & Ideal & 2000 & 2000 & 44 & 10 \\
no FC absorption & & & & & \\
Optimised & Ideal & 2000 & 1960 & 67 & 16 \\
Optimised & Ideal & 5000 & 2340 & 120 & 29
\end{tabular}

- The escape of the exhaust gas in the experimental system was warranted by a hole in the top reflector, which can be covered with a concave reflector leaving a slit for the exhaust gas flow. In the solar heated system, a hole in the top reflector is needed, through which the concentrated sunlight enters the system. These openings, which are a relevant difficulty for achieving an optical cavity, are considered in the model by using an average reflectivity of the top reflector. For an exact calculation of this relatively complicate geometry, a ray tracing calculation would be necessary.

- The emitter reflectivity $R_{\mathrm{em}}$, which is used for the calculation of a solar TPV system, was assumed being independent of the photon energy. An efficient light trapping due to the porous surface of the foam ceramic is expected, which depends on the exact geometry of the emitter. The spectral reflectance of such an emitter was not measured, up to now.

Simulations of the small gas fired TPV system with different photocells, reflectors, filters and emitters show an agreement with the experimentally achieved system efficiencies of better than $90 \%$. It is therefore expected that the listed assumptions doesn't cause any major uncertainties in the simulations results. This justifies the application of our model to estimate the efficiency of the TPV system heated with concentrated solar radiation. The simulation model allows in a convenient way to study losses that occur in a specific component of the TPV system and their effect to the system efficiency.

Table 2 gives the result of these simulations. In the first line the existing small TPV system was modelled: PSI-TPV is the photocell manufactured at Paul Scherrer Institut with a rear surface reflector. A sun radiation concentration factor of 1000 was assumed. The area of the concentrator was $5000 \mathrm{~cm}^{2}$ for all simulations. The resulting opening in the top reflector, which is needed to illuminate the emitter, had an area of $6.6 \mathrm{~cm}^{2}$. The reflectivity of the emitter was assumed being $10 \%$. A system efficiency $\eta_{\text {sys }}$ of $4.0 \%$ was obtained for this case.
In subsequent simulations several optimisations were studied to reduce losses in the system and to increase $\eta_{\text {sys }}$. Using lower doped $\mathrm{Si}$ for the photocell fabrication to avoid free carrier (FC) absorption of sub-bandgap radiation increases $\eta_{\text {sys }}$ to $5.9 \%$. Further losses are absorption in the quartz tube and radiation loss through the opening in the top reflector. In the following simulations, this opening was made smaller, by enlarging the concentration factor $c$, i.e. reducing the focus spot of the concentrated sunlight. The quartz tube was replaced by an idealised filter with an assumed transmittance of $99 \%$ for convertible radiation and a reflectance of $99 \%$ for sub-bandgap radiation. The resulting $\eta_{\text {sys }}$ was $10 \%$. To estimate an upper limit for $\eta_{\text {sys }}$ of a solar TPV system with Si photocells and $\mathrm{Yb}_{2} \mathrm{O}_{3}$ emitter based on our technology, an optimised photocells with a monochromatic efficiency of $46 \%$ at $1.25 \mathrm{eV}$ was assumed, resulting in a $\eta_{\text {sys }}$ of $16 \%$ for a concentration factor of 2000 and $29 \%$ for 5000 , respectively.

\section{Conclusion}

A $\mathrm{Yb}_{2} \mathrm{O}_{3}$ foam ceramic emitter has been developed, which fulfils the requirements for use in TPV systems. Mechanical and thermal stability up to temperatures of $1800 \mathrm{~K}$ were achieved with these emitters. The selectivity of the emitter radiation with respect to the band gap of $\mathrm{Si}$ is currently $10 \%$. Thermal-shock stability tests during up to 200 ignition cycles in the laboratory showed that the emitters posses a satisfactory thermal-cycling resistance. Long-term cycle tests are planned in the near future to verify the thermal-shock resistance over a larger number of cycles. The foam ceramic emitters were successfully tested in two prototype TPV systems. A $\eta_{\text {sys }}$ of $1 \%$ was achieved with the small prototype. In the larger prototype the $\eta_{\text {sys }}$ was about half of this required value, but it is expected to increase the $\eta_{\text {sys }}$ once the selectivity of the foam ceramics is improved or the design of the smaller prototype TPV system is adapted to that of the large one.

The use of thermophotovoltaics for the conversion of concentrated sunlight would be attractive, if a $\eta_{\text {sys }}$ value higher than that of high-quality single junction solar cells under concentration, which is $28 \%$ at present, could be achieved. Simulations show that, in principle, an efficiency in the order of $30 \%$ is achievable with a TPV system using $\mathrm{Si}$ photocells and a $\mathrm{Yb}_{2} \mathrm{O}_{3}$ emitter. However, several simplifying assumptions were made for this calculation, including optimised photocells, an ideal selective filter and a very high concentration factor of 5000. Experiments with the TPV system discussed here under concentrated sunlight are planned for the future to confirm the calculated values of $\eta_{\text {sys }}$ from the simulations.

Acknowledgements: The work was funded by the Swiss Commission of Technology and Innovation (CTI), contract No. 5692.2 EBS. 


\section{References}

[1] W.E. Horne, M.D. Morgan, V.S. Sundaram, T. Butcher. In: Thermophotovoltaic Generation of Electricity: Fifth Conf. on Thermophotovolt. Gen. of Electr. (AIP Conf. Proc., 653) ed. by T.J. Coutts, G.E. Guazzoni, J. Luther (2003) p. 91.

[2] B. Bitnar, J.-C. Mayor, W. Durisch, A. Meyer, G. Palfinger, F. von Roth, H. Sigg. In: Thermophotovoltaic Generation of Electricity: Fifth Conf. on Thermophotovolt. Gen. of Electr. (AIP Conf. Proc., 653) ed. by T.J. Coutts, G.E. Guazzoni, J. Luther (2003) p. 18.

[3] B. Bitnar, W. Durisch, J.-C. Mayor, H. Sigg, H.R. Tschudi. Sol. Energy Mater. and Solar Cells, 73 (3), 221 (2002).

[4] B. Bitnar, W. Durisch, F. von Roth, G. Palfinger, H. Sigg, D. Grützmacher, J. Gobrecht, E.-M. Meyer, U. Vogt, A. Meyer, A. Heeb. In: Next Generation Photovoltaics: High Efficiency through Full Spectrum Utilization, ed. by A. Marti, A. Luque (IOP, 2004) p. 223.

[5] B. Bitnar, W. Durisch, A. Meyer, G. Palfinger. In: Thermophotovoltaic Generation of Electricity: Fifth Conf. on Thermophotovolt. Gen. of Electr. (AIP Conf. Proc., 653) ed. by T.J. Coutts, G.E. Guazzoni, J. Luther (2003) p. 465.

[6] R. Siegel, J.R. Howell. Thermal radiation heat transfer, 2nd ed. (Hemisphere Publ. Corp., N. Y., 1981).

[7] K.W. Stone, D.L. Chubb, D.M. Wilt, M.W. Wanlass. In: Thermophotovoltaic Generation of Electricity: Second NREL Conf. on Thermophotovolt. Gen. of Electr. (AIP Conf. Proc., 358) ed. by J.P. Benner, T.J. Coutts, D.S. Ginley (1996) p. 199.

[8] Zh.I. Alferov, V.D. Rumyantsev. In: Next Generation Photovoltaics: High Efficiency through Full Spectrum Utilization, ed. by A. Marti, A. Luque (IOP, 2004) p. 19.

Редактор Л.В. Беляков 